\title{
Recursos Administrativos
}

\author{
Odete Medauar \\ Professora Livre-Docente da Faculdade \\ de Direito da Universidade de São Paulo
}

\begin{abstract}
SUMARIO: 1. Introdução - 2, Noção - 3. O recurso administrativo $e$ o controle interno da Administração - 4. O recurso administrativo $e$ o processo administrativo -5 . 0 recurso administrativo $e$ a defesa de direitos $e$ interesses de administrados - 6. Vantagens para o ladministrado - 7. Como são disciplinados nos ordenamentos - 8. o que é suscetível de recursos administrativos - 9. Quem pode interpor recurso - 10. Condigões de forma - 11. Prazo de interposigão - 12. Prazo de decisão - 13. Efeito da interposição quanto à execução do xto impugnado 14. Efeitos da decisão do recurso sobre o ato impugnado - 15. A questão da previa exaustão das vias administrativas.
\end{abstract}

\section{Introdução}

Numa época em que, pela amplitude de suas funções, o Estado, ao desempenhar sua atividade administrativa, afeta direitos e interesses dos indivíduos e num momento de "crise do Poder Judiciário", parece oportuno estudar um dos meios pelos quais se torna possível obter alteração de decisões tomadas no âmbito da Administração Pública.

Ao examinarmos o tema dos recursos administrativos, trataremos de seus aspectos gerais, ou seja, dos pontos fundamentais do seu regime jurídico geral, sem abarcar cada uma das espécies. Para melhor compreensão dos preceitos vigentes no ordenamento pátrio e da "doutrina" dos recursos administrativos mencionaremos, por vezes, o direito estrangeiro.

\section{Noção}

$\mathrm{Na}$ lição de CRETELLA JUNIOR ${ }^{1}$ recurso administrativo é o "remedium juris que consiste na provocação a reexame de um caso, na esfera administrativa, perante a mesma autoridade ou outra de superior hierarquia"

1. Tratado de Direito Administrativo, vol. VI, Ed. Forense, p. 235. 
Ao interpor recurso administrativo o indivíduo pretende que a Administração altere uma decisão adotada, para, de regra, anulá-la, revogá-la ou modificá-la parcialmente.

Tais recursos tramitam, são decididos e se esgotam no âmbito da Administração Pública, sem vinculação direta com a função jurisdicional, tendo, portanto, regime jurídico próprio, que são se confunde com as notas características dos recursos perante o Judiciário.

\section{O recurso administrativo e o controle interno da Administração}

Propiciando, por provocação do interessado, o reexame de medidas adotadas, os recursos administrativos apresentam-se como um dos modos pelos quais a Administração fiscaliza seus próprios atos para que o interesse público seja atendido e a legalidade preservada. Sob este aspecto inserem-se em estudos dedicados ao "Controle da Administração", como ocorre na obra de DEBBASCH, "Science Administrative" (3 ed., 1976, p. 649).

$\mathrm{Na}$ verdade, a vigilância exercida por órgãos superiores da hierarquia sobre atos dos subordinados foi historicamente e por longo tempo a única forma de controle incidente sobre a Administração; príncipes e depois governantes eleitos sempre invocaram e exercem direito de vigilância sobre atos dos escalōes inferiores e consentiram, paralelamente, que particulares oferecessem reclamações contra tais atos; conhecer essas reclamações configurava meio de informar-se e também de corrigir erros; bem antes de ser afirmada a necessidade de submeter a Administração ao controle por provocação, do Poder Judiciário ou a outro órgão de controle externo, já se realizava o autocontrole, a auto-regulação da Administração pela própria Administração ${ }^{2}$.

Atualmente o controle externo, sobretudo o controle jurisdicional, está organizado em toda parte, mas os meios de controle interno não desapareceram nem perderam sua utilidade.

\section{O recurso administrativo e o processo administrativo}

Os recursos administrativos aparecem mencionados também em obras ou capítulos destinados ao exame do processo ou procedimento administrativo, entendido como o conjunto de operações necessárias para que $o$ ato administrativo seja editado e produza todos os seus efeitos jurídicos. Por exemplo, nos trabalhos de CRETELLA JUNIOR (Tratado de Direito Administrativo, vol. VI, dedicado ao Processo Administrativo), VILLAR Y ROMERO (Derecho Procesal Adminis-

2. BRAIBANT, QUESTIAUX e WIENER, Le Controle de l'Administration et la Protection des Citoyens, Paris, Ed. Cujas, 1973, p. 263. 
trativo; Madrid, $2^{a}$ ed., 1948), GUY ISAAC (La Procedure Administrative Nono-Contentieuse, Paris, 1968) e HÉCTOR JORGE ESCOLA (Tratado General de Procedimiento Administrativo, Buenos Aires, 1981).

\section{O recurso administrativo e a proteção de direitos $\theta$ interesses de administrados}

Sob ângulo subjetivo encontramos os recursos administrativos considerados como instrumentos de proteção ds direitos dos cidadãos eventualmente lesados pela Administração, como afirma CARLOS S. DE BARROS JUNIOR (Recursos Administrativos, "in", Revista de Direito Administrativo, $\mathrm{n}^{\circ}$ 13, 1948, p. 41) e BRAIBANT, QUESTIAUX e WIENER (Le Controle de l'Administration et la Protection des Citoyens, p. 279). Para GARCIA DE ENTERRIA "os recursos administrativos constituem uma garantia para os indivíduos afetados por decisões da Administração na medida em que asseguram a possibilidade de reagir contra elas e, eventualmente, de eliminar o prejuízo que comportam" ${ }^{3}$.

\section{Vantagens para o administrado}

Encarados sob o aspecto objetivo, como instrumento do controle interno ou sob o prisma subjetivo, na qualidade de meio para proteção de direitos e interesses dos cidadãos ou estudados como espécie de procedimento administrativo, tais recursos oferecem algumas vantagens aos administrados, sobretudo se comparados aos meios jurisdicionais.

Apresentando-se menos formalistas e onerosos que as vias jurisdicionais, tornam-se mais acessiveis aos indivíduos ${ }^{4}$. Por outro lado, o reexame ensejado pela interposição de recurso administrativo abrange questões atinentes à oportunidade e conveniência da decisão administrativa, o que não ocorre com a apreciação pela via jurisdicional.

Expressão da relevância desses meios nos fornece o ordenamento francês, no qual o direito de interpor recurso administrativo consagrou-se como princípio geral do direito, tendo o Conselho de Estado firmado entendimento de que esse recurso existe de modo geral, em todos os assuntos, mesmo sem texto que o preveja expressamente (decisão no caso Queralt, junho de 1950); o recurso administrativo é de "direito comum", só podendo ser afastado por texto legal que o exclua de modo explícito.

Em nosso entender a mesma orientação deve predominar em todos os ordenamentos, admitindo-se, de regra, mesmo sem previsão expressa, a recorribilidade administrativa das decisões da Administração.

3. Curso de Derecho Administrativo, vol. II, Madrid, 1982, p. 436.

4. BRAIBANT, QUESTIAUX e WIENER, Le Controle de l'Administration et la Protection des Citoyens, p. 263. 
A importância de tais meios não deve, entretanto, conduzir a enganos quanto a sua eficácia na proteção dos direitos dos cidadãos. $O$ fato de que é a própria Administração quem decide o recurso; a inexistência, em geral, da obrigação de decidir e também a possivel solidariedade entre os diversos escalões da hierarquia permitem ponderar que o recurso administrativo é remédio limitado. Para GARCIA DE ENTERRIA", "os recursos administrativos são, sem dúvida, uma garantia para os particulares, uma garantia nada desprezivel, mas uma garantia limitada que em nenhum caso é lícito supervalorizar".

\section{y Como são disciplinados nos ordenamentos}

Presentes em todos os ordenamentos, têm modos diversificados de regulação. Há direitos em que o regime jurídico dos recursos administrativos encontra-se rigorosamente fixado pelo legislador nos Códigos ou Leis de Procedimento Administrativo, como ocorre na Espanha, Argentina e Alemanha Federal. Em outros, a exemplo da França, a disciplina foi, pouco a pouco, modelada pela jurisprudência. $\mathrm{E}$ existem ordenamentos nos quais os recursos administrativos têm disciplina incompleta. É o caso do direito brasileiro, em que se estabelecem normas para recursos de funcionários públicos no texto dos estatutos (Estatuto dos Funcionários Públicos Civis da União - Lei no 1.711, de 28-10-1952 - arts. 164 a 173; Estatuto dos Funcionários Públicos Civis do Estado de São Paulo Lei $n^{\circ}$ 10.261, de 28-10-1968 arts, 239 a 240) e para recursos em alguns assuntos específicos, cuja decisão em geral compete também a órgãos específicos da Administração, cuja missão precípua é decidir apelos administrativos, como ocorre, por exemplo, em matéria fiscal (recursos perante Tribunais de Impostos e Taxas). Nos textos que regulam licitações e nos editais de concursos públicos é habitual a menção a recursos administrativos, somente com indicação dos prazos de interposição e autoridade competente para decidir.

\section{O que é suscetível de recursos administrativos}

Contra que atuações ou atos da Administração admitem-se recursos? Os vários aspectos dessa indagação são discutidos na doutrina, com muitas divergências, que se refletem no direito legislado dos vários ordenamentos.

a) Uma das questões controvertidas diz respeito à recorribilidade das chamadas "operações materiais" da Administração, das simples atuações concretas, tais como, jogar pedriscos em ruas não asfaltadas, guinchar veículos, tapar buracos do asfalto, etc.

5. Chrso de Derecho Administrativo, vol. II, Madrid, 1982, p. 438. 
No entendimento de GUY ISAAC $^{6}$ só cabe recursos contra decisões jurídicas, contra atos administrativos. VILLAR Y ROMERO ?, na mesma linha afirma que o recurso origina-se sempre de ato administrativo que se queira desfazer; recursos sempre impugnam atos.

$\mathrm{Na}$ verdade parece difícil conceber recurso administrativo contra operação material; de regra, tais atuações se exaurem de imediato e também são irreversíveis. Aos indivíduos que se considerem lesados resta a utilização de requerimentos administrativos ou das vias jurisdicionais para solicitar reparação de danos. No entanto, caso as operações materiais sejam reversíveis ou então apresentem-se dotadas de continuidade, com atuações que se repetem várias vezes, entendemos ser cabível recorrer de tais operações, para que a autoridade administrativa determine seu desfazimento ou sua sustação.

b) Outro ponto debatido na doutrina diz respeito aos atos internos, tais como circulares, ordens de serviço, instruções, atinentes à organização dos serviços. Grande parte da doutrina manifesta-se pelo não cabimento de apelos contra tais atos, vistos esgotarem-se no âmbito das repartições e não lesarem direito ou interesse pessoal de administrado algum. É a opinião de CARLOS S. DE BARROS JUNIOR \&, LAFAYETTE PONDE ${ }^{9}$ e VILLAR Y ROMERO ${ }^{\text {1a. }}$. Referidos autores certamente firmaram entendimento na suposição de que tais atos sejam editados com as finalidades apontadas na doutrina, visando, portanto, somente à ordenação interna de serviços, sem repercussão alguma fora do recinto das repartições. Com tais objetivos, não há que se falar de recursos contra tais atos, emanados de autoridades hierarquicamente superiores a subordinados. Mas se os atos conceituados como internos afetarem direitos de particulares, como sói acontecer no Brasil, parece-nos ser possível a interposição de recursos.

c) Pode-se recorrer da inércia ou silêncio da Administração? A inércia ou silêncio da Administração muitas vezes pode acarretar prejuízos tão graves aos indivíduos quanto um ato ilegal. Muitos ordenamentos admitem recurso quanto a Administração, após prazo determinado, não tomou decisão que deveria editar ou não respondeu a pedido que lhe foi dirigido, equivalendo a inércia 2 o silêncio a um indeferimento. Assim, por exemplo, no direito francês; após o prazo de quatro meses sem que haja decisão, o interessado pode recorrer ao superior hierárquico da autoridade que deveria ter emitido manifestação. O Estatuto dos Funcionários Públicos Civis do Estado de São Paulo, no art. 239, V, prevê o cabimento do recurso hierárquico quando o apelo dirigido à mesma autoridade responsável pelo ato impugnado não receber decisão no prazo legal (30 dias), equivalendo o silêncio ao indeferimento.

6. La Procedure Administrative Non-Contentieuse, Paris, 1968.

7. Derecho Procesal Administrativo, Madrid, 1948, p. 124.

8. Recursos Administrativas, "in" RDA n? 13, 1948, p. 43.

9. Principios Gerais do Recurso Administrativo, RDA no 23, 1951, p. 21.

10. Derecho Procesal Administrativo, p. 124 e 126. 
A possibilidade de recurso contra a inércia ou silêncio deve sempre existir e na ausência de prazo para a autoridade decidir o interessado aguardará tempo razoável, após o qual apelará ao órgão imediatamente superior.

\section{Quem pode interpor recurso}

A questão fundamental que se coloca no tocante ao sujeito que pode recorrer está na necessidade ou não de direito ou interesse individual, próprio, na alteração da decisão anterior.

No direito italiano exige-se que o "ato administrativo incida sobre um interesse próprio do recorrente, individual e não geral à coletividade, uti singulus e non uti civis" ${ }^{11}$. O mesmo vigora no ordenamento espanhol, segundo expõe MARTIN MATEO (Manual de Derecho Administrativo, 1980, p. 388).

Para o francês GUY ISAAC a possibilidade de interposição não está sujeita a condição alguma relativa ao interesse, sendo nesse sentido a jurisprudência do Conselho de Estado francês. Segundo afirmam BAIBANT, QUESTIAUX e WIENER na maioria dos ordenamentos o "recurso é aberto a qualquer pessoa interessada na decisão, mesmo que não seja sua principal destinatária" ${ }^{12}$.

Tendo em vista que a Administração atua para atender de modo imediato, contínuo e concreto, ao interesse da coletividade e ante o fato de que decisões de autoridades administrativas podem afetar interesses coletivos ou difusos, parece-nos que a possibilidade de recorrer deve guardar relação com a repercussão ou alcance dos efeitos da medida impugnada. Se a decisão da Administração afetar diretamente só uma determinada pessoa, a esta caberá, com exclusividade, a interposição de recurso. Caso o ato atinja diretamente um grupo de interessados ou a coletividade, a qualquer um dos integrantes desse grupo ou da coletividade seria aberta a via do recurso administrativo para tentar obter sua alteração.

\section{Condicões de forma}

Inexiste, quanto aos recursos administrativos, rigorismo de forma. De regra não se exige forma especial, salvo expressa previsão de lei. Devem apresentar-se por escrito, embora nem todo escrito possa ser considerado recurso. LAFAYETTE PONDÉ bem observa que se tem recusado possa o recurso ter a forma de carta e cita manifestação do

11. LANDI E POTENZA, Manuale di Diritto Amministrativo, Miláo, 6* ed., 1978, p. 641. Já em 1901, ORLANDO, no seu trabalho "La Giustizia Amministrativa", inserido no vol. III do Primo Trattiado Completo di Diritto Amministrativo Italiano afirmava que o "recurso deve emanar de quem tenha um interesse pessoal na anulação ou modificação do ato impugnado" (p. 678).

12. Le Controle de l'Administration et la Protection des Citoyens, p. 273. 
DASP, no sentido de que "a carta particular não é meio hábil para pleitear decisões administrativas, como repetidamente tem sido decidido" ${ }^{13}$.

É de praxe que o instrumento de recurso contenha indicação do recorrente, da autoridade que editou a decisão impugnada, do ato recorrido, dos motivos pelos quais é solicitado o reexame e contenha também manifestação de ser revista a medida.

\section{Prazo de interposição}

Havendo prazo para interposição, este tem caráter peremptório. A não observância dos prazos de recurso é considerada de modo diverso, de acordo com a maior ou menor rigidez de tratamento da matéria nos diferentes ordenamentos. Assim, por exemplo, no direito espanhol a perda dos curtos prazos para recorrer 15 dias para o hierárquico e 30 dias para o pedido de reconsideração) acarreta não somente a impossibilidade para sempre de recorrer, mas também a condição de ato sanado de vícios à decisão da Administração, que permanece, desse modo, inatacável, não podendo o interessado utilizar-se da via jurisdicional para combatê-lo ${ }^{14}$; a regra, vigente no direito espanhol, de prévio esgotamento da via administrativa pela interposição de recursos, traz conseqüências graves no caso de não cumprimento dos prazos recursais.

Nos ordenamentos francês e belga não há limite de tempo para interposição de recurso administrativo; mas se o interessado pretender ir à jurisdição administrativa, se a decisão do recurso não favorecê-lo, deverá ingressar com o recurso no prazo fixado para ajuizar a ação, pois assim procedendo terá prorrogado o prazo da via jurisdicional até solução do recurso.

No direito brasileiro não há uniformidade nos prazos de recurso, mesmo no âmbito da Administração de cada esfera política; cada lei ou decreto regular de um tipo de assunto estabelece prazos especificos. Algumas tendências podem ser apontadas; os prazos de recurso para funcionários, relativos, portanto a decisões sobre direitos e deveres funcionais, são mais longos que os prazos de recursos contra atos do procedimento licitatório ou que os prazos de recursos de lista de classificação em concursos de ingresso ou acesso.

Aspecto que enseja indagação no ordenamento pátrio, em que não há lei geral de procedimento administrativo e no qual o recurso administrativo é um meio a mais oferecido ao particular para defesa de seus direitos, é o da conduta da Administração ante recursos oferecidos fora do prazo. À vista do preceito da peremptoriedade dos prazos de interposição a Administração, de regra não conhece do re-

13. Principios Gerais do Recurso Administrativo, "in" RDA, n' 23, 1951, p. 22.

14. GARCIA DE ENTERRIA, Curso de Derecho Administrativo, vol. II, 1982, p. 439. 
curso; mas, tendo em vista que o recurso administrativo também é meio de exercício do controle interno, se a autoridade administrativa verificar, pela leitura do recurso, a incidência de ilegalidade ou de medidas que ferem o interesse público, poderá, de ofício, determinar a revisão do caso.

No tocante ao momento em que se inicia o curso dos prazos, vigora a regra da data de publicação oficial ou data em que o interessado conheceu a decisão, no caso de não divulgada publicamente.

\section{Prazo de decisão}

Os ordenamentos que têm códigos ou leis gerais de procedimento administrativo fixam prazos uniformes para a autoridade decidir os recursos; nos ordenamentos sem códigos ou leis gerais, para cada matéria podem ser estabelecidos prazos diferentes. No entanto, em qualquer dos modos de tratamento, não há, para a autoridade administrativa, consequiência alguma pelo desatendimento dos termos. Para salvaguarda dos direitos dos administrados, especialmente quando há vínculo entre a via administrativa e a via jurisdicional, costuma-se equiparar a indeferimento ou rejeição o silêncio da autoridade após certo lapso de tempo. Por exemplo: o Estatuto dos Funcionários Públicos Civis do Estado de São Paulo fixa o prazo de trinta dias para a decisão do pedido de reconsideração; decorrido esse tempo, sem decisão, o funcionário poderá interpor recurso hierárquico. No direito espanhol após três meses e um mês respectivamente da interposição do recurso hierárquico e do pedido de reconsideração, sem que haja comunicação de sua solução, consideram-se rejeitados os recursos.

\section{Efeito da interposição quanto à execução do ato impugnado}

O preceito predominante é o da não suspensão dos efeitos do ato impugnado pela interposição do recurso. Essa regra encontra fundamento na presunção de legalidade do ato administrativo, na sua característica de auto-executoriedade e no princípio de que a Administração atua para atender ao interesse público. Entretanto, caso a executoriedade possa acarretar, ao recorrente, dano irreparável, a autoridade administrativa determinará a suspensão da eficácia do ato. No direito brasileiro a norma é a não suspensão dos efeitos, salvo o caso de texto expresso que estabeleça, em certa matéria, o efeito suspensivo do recurso. Exemplo de efeito suspensivo encontra-se na Lei paulista de licitações e contratos - Lei n 89, de 27-12-1972 que deu efeito suspensivo para o recurso contra habilitação ou inabilitação de licitante (art. 68, inciso I, alínea "a").

No direito estrangeiro aparecem algumas exceções à não suspensividade. No direito austríaco a suspensão é a regra, quando não foi excluída por uma lei ou afastada pelo órgão de recurso por razões 
de urgência devidamente justificadas; na Alemanha Federal a interposição de recurso impede, em princípio, a execução dos atos que imponham obrigações a um particular ${ }^{15}$.

\section{Efeitos da decisão do recurso sobre o ato impugnado}

O recurso administrativo visa a provocar o reexame de uma decisão da Administração, pretendendo, o interessado, em geral, alteração de medida anterior.

A solução do recurso expressa-se por um ato administrativo no qual a autoridade competente pode não dar provimento ao recurso ou, acolhendo-o, pode determinar a anulação, revogação ou modificação parcial do ato.

Em síntese, a solução do recurso vai acarretar ou a manutenção da medida impugnada ou sua alteração.

Se à autoridade competente para conhecer o recurso atribui-se o poder de alterar o ato impugnado, cabe indagar se essa faculdade é ilimitada.

$\mathrm{O}$ interessado ao interpor recurso evidentemente busca benefícios, melhorias, vantagens, reconhecimento de direitos, satisfação de inte. resses.

O recurso limitaria o poder de decisão da autoridade competente somente aos termos aí contidos? Pode a Administração, ao decidir o recurso, piorar a situação do interessado? Ou melhorá-la?

Essa questão tradicionalmente é discutida sob o ângulo da reforma para pior, ou seja, da "reformatio in pejus"

Ao estudarem o problema BRAIBANT, QUESTIAUX e WIENER ${ }^{16}$ observam que o recurso administrativo pode ser considerado sob ângulo essencialmente subjetivo, como instrumento de defesa de direitos e interesses do indivíduo; em decorrência a Administração seria obrigada a apreciar o recurso nos termos em que foi interposto; o recorrente não teria agravada sua situação.

Sob prisma objetivo o recurso configura meio de assegurar a regularidade e correção da atividade administrativa, cabendo à autoridade competente não só apreciar as alegações do recurso, mas reexaminar, no seu conjunto, "o ato impugnado; por conseguinte, a proteção de interesses do administrado é apenas um elemento da situação submetida ao órgão de recurso; o recurso desencadeia o controle, mas não condiciona a extensão do controle" ${ }^{17}$. Surgindo a

15. BRAIBANT, QUESTIAUX e WIENER, Le Controle de l'Adminisiration et la Protection des Citoyens, p. 276.

16. Le Controle de l'Administnation et la Protection des Citoyen,, .. 278.

17. BRAIBANT, QUESTIAUX e WIENER, op. cit., p. 278. 
necessidade de reformar para pior, há conflito entre o aspecto subjetivo e o objetivo do recurso.

A tendência geral faz prevalecer o aspecto objetivo sobre o subjetivo, admitindo a "reformatio in pejus".

$\mathrm{Na}$ França o Conselho de Esstado firmou jurisprudência no sentido de que a autoridade superior tem a faculdade de reformar ou anular decisão do subordinado mesmo em sentido contrário à pretensão do recorrente. Nos ordenamentos austríaco, alemão e italiano, da mesma forma, vigora a ilimitação para reformar. O direito brasileiro admite igualmente a "reformatio in pejus", excepcionando-a em poucas hipóteses, como ocorre com a revisão do procedimento administrativo disciplinar; por exemplo, o Estatuto dos Funcionários Públicos do Estado de São Paulo (art. 313) e do Município de São Paulo - Lei $\mathrm{n}^{\circ}$ 8.989, de 29-10-1979 - (art. 220, $\S 2^{\circ}$ ) vedam que a pena seja agravada em conseqüência da revisão.

Há ordenamentos em que vigora o preceito inverso. Assim, no direito espanhol jurisprudência fixada a partir de 1972 proíbe a "reformatio in pejus" de atos administrativos objeto de recurso; as exceções deverão estar previstas em lei ${ }^{18}$.

Quanto à possibilidade de reformar para melhor, concedendo-se ao recorrente mais do que solicitou, é amplamente admitida, não se registrando então, conflito entre os aspectos subjetivo e objetivo do recurso.

\section{A questão da prévia exaustão das vias administrativas}

O problema da exigência de exaurir primeiro as vias administrativas para depois utilizar a via jurisdicional aparece suscitado nos estudos dedicados aos recursos administrativos, porque mediante tais recursos obtém-se posição definitiva da Administração em determinado caso.

O tema surge tratado também sob a designação de "coordenação das garantias jurisdicionais e não contenciosas" ${ }^{19}$ sob o nome de "aticulação da via administrativa de recursos e da via jurisdicional" ${ }^{20}$.

A questão é de grande relevo, pois, como afirma ADA PELLEGRINI GRINOVER "a exaustão das vias administrativas configura uma das condições da ação e exatamente o interesse de agir" ${ }^{21}$, trazendo

18. GARCIA DE ENTERRIA, Curso de Derecho Administrativo, vol. II, 1982, p. 457. Referido autor, vendo o recurso predominantemente como garantia para o administrado, discorda da possibilidade da "reformatio in pejus", aplaudindo a jurisprudência do seu país, pois contradiz a "própria essência institucional do recurso administrativo" (p. 455).

19. GUY ISAAC, $L a$ Procédure Administrativê Non-Contentieuse, p. 647.

20. GARCIA DE ENTERRIA, Curso de Derecho Administrativo, vol. II, 1982, p. 438.

21. O Contencioso Administrativo na Emenda no 7/197\%, "in" O Processo em sua Unidade, 1978, p. 63-64. 
repercussão no acesso ao Poder Judiciário para defesa de direitos violados.

Nota-se, ao estudar o direito estrangeiro, diversidade acentuada no modo de disciplinar matéria. Examinaremos, de modo sintético, o sistema de três ordenamentos para depois considerar o tratamento dado pelo direito pátrio.

No direito francês exige-se, para o ingresso na jurisdição administrativa, uma decisão prévia da Administração, uma única instância administrativa, com a finalidade de obtenção de pronunciamento anterior da Administração a respeito do caso. A obrigatoriedade da "décision préalable" teria aspectos vantajosos, segundo GUY ISAAC: para a Administração - não ser conduzido à via jurisdicional sem antes tomar posição sobre o assunto; para o particular - impedi-lo de ingressar na jurisdição administrativa para discutir matérias que a tanto não se prestam ou pontos que a autoridade estaria disposta a satisfazer; para o juiz - facilitar sua missão" ${ }^{22}$.

A exigência de decisão prévia não se impõe, no entanto, para o ingresso aos tribuais da jurisdição ordinária; somente para a jurisdição administrativa (contencioso administrativo).

$\mathrm{E}$ a obrigatoriedade da decisão prévia não se confunde com a exaustão das vias administrativas ou exaustão dos recursos administrativos. No direito francês, a regra é a não obrigatoriedade de interposição de recursos administrativos, salvo alguns casos, como por exemplo, em matéria fiscal e previdenciária.

No direito italiano, não se impõe o prévio esgotamento tratando-se de atos lesivos de direitos subjetivos públicos, a serem apreciados pela jurisdição ordinária; cogitando-se de interesses legítimos, o acesso à jurisdição administrativa depende da prévia exaustão das vias administrativas.

$\mathrm{Na}$ Espanha o ingresso na via contenciosa administrativa condiciona-se ao esgotamento dos recursos administrativos que se apresentam, na expressão de GARCIA DE ENTERRIA, como "um privilégio da Administração e um correlato ônus para os administrados" ${ }^{23}$. O mesmo autor tece crítica a esse sistema, pregando a revisão da exigência, para tornar facultativa a via recursal administrativa, especialmente com a finalidade de facilitar o acesso ao Poder Judiciário.

No direito brasileiro, pode-se afirmar, vigora o princípio da não exigência de exaustão prévia das vias administrativas.

A segunda parte do $\S 4^{\circ}$ do art. 153 da Constituição Federal aventa a possibilidade de condicionar-se o ingresso em juízo ao prévio esgotamento das vias administrativas, desde que não exigida garantia de

22. La Procédure Administrative Non-Contentieuse, p. 658 e segts.

23. Op. cit., p. 438. 
instância, nem ultrapassado o prazo de cento e oitenta dias para a decisão do pedido. Mas, a possibilidade não se concretizou até o presente, nem de modo genérico, nem em matérias específicas (arts. 110 e 203 da Constituição Federal).

No momento em que se pretender, em qualquer assunto, condicionar o acesso ao Judiciário à prévia exaustão das vias administrativas a observação de ADA PELLEGRINI GRINOVER deve prevalecer: "o $\S 4$ do art. 153 constitui um todo, que deverá ser interpretado em harmonia com o regime constitucional: a exaustão das vias administrativas, prevista na segunda parte do dispositivo, só será legítima na medida em que não infringir a primeira parte do artigo, que garante o acesso às vias jurisdicionais em caso de lesão de direitos individuais. Toda vez que o prévio esgotamento das vias administra. tivas acarretar tal lesão, haverá de imediato interesse de agir (interesse-necessidade) e conseqüentemente possibilidade imediata de acesso ao Judiciário" ${ }^{24}$.

No tocante ao impedimento de interposição de mandado de segurança contra ato de que caiba recurso administrativo com efeito suspensivo, independe de caução, configura, a nosso ver exceção ao preceito de não exigência de exaustão prévia, devendo ser entendida, mesmo assim, nos termos das considerações supracitadas, expendidas por ADA PELLEGRINI GRINOVER. 